\title{
Risk factors for chronic hydrocephalus in patients with intracerebral hemorrhage complicated by coma after emergency hematoma removal
}

\author{
Hai-Tao Yuan ${ }^{1}$, Jun Feng ${ }^{2}$, Qian Wang ${ }^{3}$ \\ ${ }^{1}$ Department of Neurosurgery, People's Hospital of Dongxihu District, Wuhan, China; ${ }^{2}$ Department of Neurosurgery, Union Hospital Tongji \\ Medical College Huazhong University of Science and Technology, Wuhan, China; ${ }^{3}$ Department of Hospital Administration, The Third People's \\ Hospital of Gansu Province, Lanzhou, China \\ Contributions: (I) Conception and design: HT Yuan, J Feng; (II) Administrative support: Q Wang; (III) Provision of study materials or patients: All \\ authors; (IV) Collection and assembly of data: All authors; (V) Data analysis and interpretation: All authors; (VI) Manuscript writing: All authors; (VII) \\ Final approval of manuscript: All authors. \\ Correspondence to: Jun Feng. Department of Neurosurgery, Union Hospital Tongji Medical College Huazhong University of Science and Technology, \\ Wuhan 430022, China. Email: 1fengjun@sina.com; Qian Wang. Department of Hospital Administration, The Third People’s Hospital of Gansu \\ Province, No. 763, Jiatan Road, Chengguan District, Lanzhou 730020, China. Email: wangqian_2021@sina.com.
}

Background: The cerebrospinal fluid circulation of patients with intracerebral hemorrhage (ICH) can be blocked by blood clots, resulting in acute hydrocephalus. However, current research on chronic hydrocephalus $(\mathrm{CH})$ is lacking.

Methods: A total of 253 patients with ICH combined with coma treated at The Third People's Hospital of Gansu Province after emergency hematoma removal from January 2018 to January 2020 were included. Patients were divided into the $\mathrm{CH}$ group $(n=48)$ and the control group $(n=205)$ depending on whether hydrocephalus occurred or not within 3-12 months after operation. The main clinical characteristics of the two groups were compared, and the risk factors for $\mathrm{CH}$ were analyzed. Counting data of the two groups were expressed as "n (\%)", and multivariate logistic regression analysis was used to explore the risk factors for $\mathrm{CH}$.

Results: Compared with the control group, the proportion of patients with modified Graeb score $\geq 5$ points in the $\mathrm{CH}$ group increased significantly $(52.08 \%$ vs. $21.95 \%, \mathrm{P}=0.000)$. The proportion of patients with preoperative cerebral hernia increased significantly $(37.5 \%$ vs. $19.51 \%, \mathrm{P}=0.008)$. The proportion of patients with preoperative obstructive hydrocephalus increased $(43.75 \%$ vs. $24.39 \%, \mathrm{P}=0.007)$. The proportion of patients with postoperative subdural effusion increased (41.67\% vs. 13.66\%, $\mathrm{P}=0.000)$. Multivariate logistic regression analysis showed that a modified Graeb score $\geq 5$ points and postoperative subdural effusion were risk factors for the formation of $\mathrm{CH}$ in patients with $\mathrm{ICH}$ complicated by coma after emergency hematoma removal $(\mathrm{P}<0.05)$. The modified Graeb score has diagnostic value for the formation of $\mathrm{CH}$ in patients with ICH combined with coma after emergency hematoma removal, and the area under the curve was 0.653 $[\mathrm{P}=0.001,95 \%$ confidence interval (CI): 0.561-0.744]. There was no significant difference in preoperative neurological deficit score between the control group and the $\mathrm{CH}$ group $(19.75 \pm 3.03$ vs. 19.86 \pm 3.01 , $\mathrm{P}=0.113)$. Compared with the control group, the neurological deficit score at 12 months after operation in the $\mathrm{CH}$ group was significantly higher $(12.73 \pm 2.99$ vs. $10.64 \pm 2.82, \mathrm{P}=0.000)$.

Conclusions: A modified Graeb score $>5$ points and postoperative subdural effusion are risk factors for the formation of $\mathrm{CH}$ in patients with $\mathrm{ICH}$ combined with coma after emergency hematoma removal. The formation of $\mathrm{CH}$ affects postoperative neurological rehabilitation.

Keywords: Intracerebral hemorrhage (ICH); hematoma removal; chronic hydrocephalus $(\mathrm{CH})$; risk factors

Submitted Oct 29, 2021. Accepted for publication Jan 14, 2022.

doi: $10.21037 /$ atm-22-128

View this article at: https://dx.doi.org/10.21037/atm-22-128 


\section{Introduction}

Intracerebral hemorrhage (ICH) is a common cardiovascular and cerebrovascular disease among middle-aged people and the elderly. ICH is an important risk factor for death (1-3). In recent years, as the incidence of hypertension, diabetes, and hyperlipidemia increases, so does the incidence of ICH. Some patients with large amounts of bleeding need emergency hematoma removal. For such patients, hydrocephalus is often complicated after operation, which seriously affects neurological recovery $(4,5)$. Postoperative hydrocephalus can be divided into acute hydrocephalus and chronic hydrocephalus $(\mathrm{CH})$. Acute hydrocephalus usually occurs within 3 days after operation, caused by sudden disturbance of cerebrospinal fluid circulation. Without active treatment, it may gradually develop into $\mathrm{CH}$. The most of the reasons of Acute hydrocephalus are due to the obstruction of some parts of cerebrospinal fluid circulation pathway. $\mathrm{CH}$ is common and has complex etiologies, but the pathogenic factors affect cerebrospinal fluid circulation slowly. Some patients can develop $\mathrm{CH}$ without obvious ventricular system obstruction, which mostly occurs during 3-12 months after operation. Clinically, it can be manifested as the expansion of the whole ventricular system with blunt frontal angle, resulting in cognitive dysfunction, abnormal gait, incontinence, epilepsy, and visual impairment. If the $\mathrm{CH}$ is not treated in time, it can lead to irreversible neurological impairment $(6,7)$. Current study had evaluated the risk factors of $\mathrm{CH}$ in patients with aneurysmal subarachnoid hemorrhage (8). However, it did not focus on patients with ICH complicated by coma after emergency hematoma removal. Current research mainly focuses on acute hydrocephalus, so there are limited studies on the formation of $\mathrm{CH}$ in patients with ICH combined with coma after emergency hematoma removal. Therefore, the aim of the present study was to explore the risk factors for $\mathrm{CH}$ in patients with ICH combined with coma after emergency hematoma removal, to provide evidence for reducing the incidence of $\mathrm{CH}$.

We present the following article in accordance with the STARD reporting checklist (available at https://atm. amegroups.com/article/view/10.21037/atm-22-128/rc).

\section{Methods}

\section{General data}

A total of 253 patients with ICH combined with coma treated at The Third People's Hospital of Gansu Province after emergency hematoma removal from January 2018 to January 2020 were included. Patients were divided into the $\mathrm{CH}$ group $(\mathrm{n}=48)$ and the control group $(\mathrm{n}=205)$ depending on whether hydrocephalus occurred or not within 3-12 months after operation.

The inclusion criteria were as follows: (I) spontaneous ICH; (II) coma; (III) new intracranial hemorrhage confirmed by brain computed tomography (CT); and (IV) complete clinical data. The exclusion criteria were as follows: (I) cerebral hemorrhage caused by craniocerebral trauma or aneurysm rupture; (II) intracranial infection, including encephalitis, meningitis, and ventriculitis; (III) patients with epidural hematoma, subdural hematoma, and arachnoid cyst; (IV) patients aged $<18$ years; and (V) survival time and follow-up time $<1$ year.

All procedures performed in this study involving human participants were in accordance with the Declaration of Helsinki (as revised in 2013). The study was approved by institutional ethics board of The Third People's Hospital of Gansu Province (No. 2020-178). Individual consent for this retrospective analysis was waived.

\section{Diagnostic criteria}

For $\mathrm{CH}$, patients with ICH combined with coma after emergency hematoma removal were followed up in the outpatient department. Patients underwent intracranial CT plain scan within 3-12 months after onset of ICH. If the following criteria were met, the patient was diagnosed as $\mathrm{CH}$ : (I) ventricular enlargement with blunt frontal angle; (II) bilateral frontal angle diameter or cranial diameter (Evans' index) $>0.33$; (III) blurred ventricular margin; and (IV) paraventricular low-density halo ring.

\section{Observational indicators}

The observational indicators were as follows: (I) general information, including age, sex, body mass index (BMI), hypertension, diabetes mellitus, and hyperlipidemia; (II) bleeding site, amount of bleeding, Glasgow Coma Scale, modified Graeb score, preoperative cerebral hernia, preoperative obstructive hydrocephalus, preoperative subarachnoid hemorrhage, postoperative subdural effusion, and operation method; and (III) neurological deficit score.

\section{Evaluation criteria}

The evaluation criteria were as follows: (I) Glasgow Coma 
Table 1 Comparison of general data between the two groups

\begin{tabular}{|c|c|c|c|c|c|c|}
\hline Category & Age ( $\geq 65$ years old) & Sex (male) & $\mathrm{BMI}\left(\geq 30 \mathrm{~kg} / \mathrm{m}^{2}\right)$ & Hypertension & Diabetes & Hyperlipidemia \\
\hline Control group $(n=205)$ & $112(54.63)$ & $132(64.39)$ & 59 (28.78) & $148(72.20)$ & $105(51.22)$ & $176(85.85)$ \\
\hline$\chi^{2}$ value & 0.215 & 0.001 & 0.275 & 0.971 & 0.023 & 0.088 \\
\hline$P$ value & 0.643 & 0.980 & 0.600 & 0.324 & 0.879 & 0.766 \\
\hline
\end{tabular}

Data were expressed as $\mathrm{n}(\%)$. BMI, body mass index; $\mathrm{CH}$, chronic hydrocephalus.

Scale: the patient's consciousness at admission was evaluated according to the Glasgow Coma Scale, with a maximum of 15 points and a minimum of 3 points. The lower the score, the more serious the condition is; (II) modified Graeb score: according to the modified Graeb score, the amount of intraventricular hemorrhage, the number of hemorrhagic ventricles, and the degree of ventricular dilatation were semi-quantitatively evaluated by brain CT at admission. The highest score is 32 points. The higher the score, the more serious the condition; and (III) neurological deficit score: the neurological deficit score was evaluated at admission and 12 months after operation to evaluate the state of neurological deficit and the impact of $\mathrm{CH}$ on neurological deficit.

\section{Statistical analysis}

SPSS version 26.0 (IBM, Armonk/Chicago, USA) was used for the data analysis. Counting data of the two groups were expressed as " $\mathrm{n}(\%)$ ", and multivariate logistic regression analysis was used to explore the risk factors for $\mathrm{CH}$. $\mathrm{P}<0.05$ indicated a statistically significant difference.

\section{Results}

\section{Comparison of general data between the two groups}

There was no significant difference in terms of age, sex, BMI, hypertension, diabetes, and hyperlipidemia between the control group and the $\mathrm{CH}$ group $(\mathrm{P}>0.05)$ (Table 1).

\section{Comparison of disease severity between the two groups}

Compared with the control group, the proportion of patients with modified Graeb score $\geq 5$ points in the $\mathrm{CH}$ group increased significantly ( $52.08 \%$ vs. $21.95 \%, \mathrm{P}=0.000$ ). The proportion of patients with preoperative cerebral hernia increased significantly (37.50\% vs. $19.51 \%, \mathrm{P}=0.008)$.
The proportion of patients with preoperative obstructive hydrocephalus increased ( $43.75 \%$ vs. $24.39 \%, \mathrm{P}=0.007)$. The proportion of patients with postoperative subdural effusion increased ( $41.67 \%$ vs. $13.66 \%, \mathrm{P}=0.000$ ) (Table 2).

\section{Risk factors for $\mathrm{CH}$ in patients with ICH combined with coma after emergency bematoma removal}

Multivariate logistic regression analysis showed that a modified Graeb score $\geq 5$ points and postoperative subdural effusion were risk factors for the formation of $\mathrm{CH}$ in patients with ICH complicated by coma after emergency hematoma removal $[\mathrm{P}=0.014,95 \%$ confidence interval $(\mathrm{CI}): 1.419-$ 23.732 and $\mathrm{P}=0.014,95 \%$ CI: 1.496-36.358] (Tables 3,4).

\section{Diagnostic value of modified Graeb score for $\mathrm{CH}$ in patients with ICH combined with coma after emergency hematoma removal}

The modified Graeb score has certain diagnostic value for the formation of $\mathrm{CH}$ in patients with $\mathrm{ICH}$ combined with coma after emergency hematoma removal, and the area under the curve was 0.653 ( $\mathrm{P}=0.001,95 \%$ CI: 0.561-0.744) (Figure 1).

\section{Effect of CH on neurological function in patients with ICH combined with coma after emergency bematoma removal}

There was no significant difference in preoperative neurological deficit score between the control group and the $\mathrm{CH}$ group $(19.75 \pm 3.03$ vs. $19.86 \pm 3.01, \mathrm{P}=0.113)$. Compared with the control group, the neurological deficit score at 12 months after operation in the $\mathrm{CH}$ group was significantly higher $(12.73 \pm 2.99$ vs. $10.64 \pm 2.82, \mathrm{P}=0.000)$ (Table 5).

\section{Discussion}

$\mathrm{CH}$ is a common complication after acute $\mathrm{ICH}(9,10)$, and 
Table 2 Comparison of disease severity between the two groups

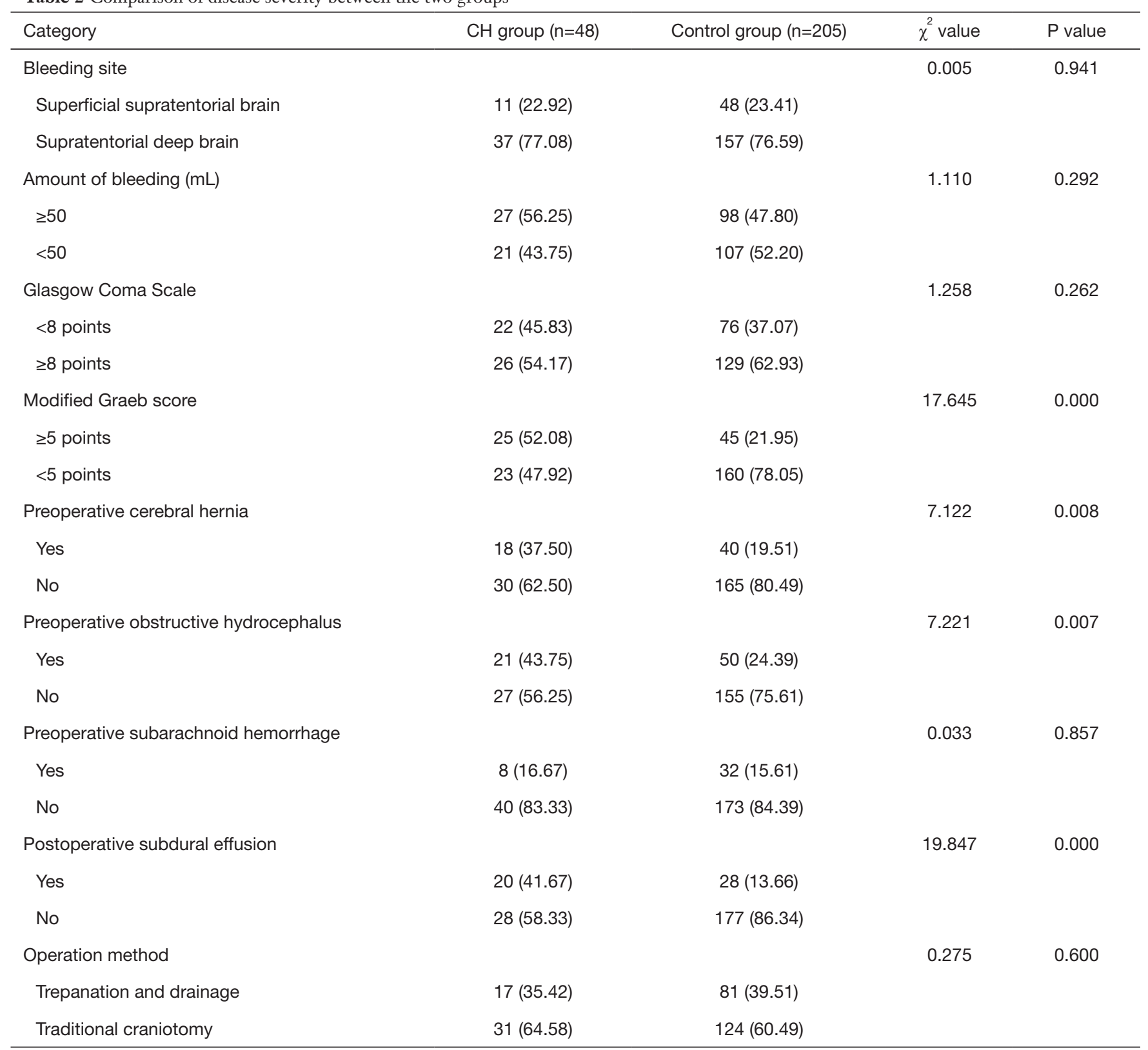

Data were expressed as $\mathrm{n}(\%)$. $\mathrm{CH}$, chronic hydrocephalus.

Table 3 Evaluation of risk factors for $\mathrm{CH}$

\begin{tabular}{|c|c|c|}
\hline Factor & Evaluation 1 & Evaluation 2 \\
\hline Modified Graeb score & $\geq 5$ points & $<5$ points \\
\hline Preoperative cerebral hernia & Yes & No \\
\hline $\begin{array}{l}\text { Preoperative obstructive } \\
\text { hydrocephalus }\end{array}$ & Yes & No \\
\hline Postoperative subdural effusion & Yes & No \\
\hline
\end{tabular}

$\mathrm{CH}$, chronic hydrocephalus. is more common in patients with secondary ventricular hemorrhage. $\mathrm{CH}$ seriously affects the neurological rehabilitation of patients, and can lead to death in severe cases. At present, there is no effective treatment for $\mathrm{CH}$, so it is particularly important to prevent it. Identifying the risk factors for $\mathrm{CH}$ is the basis of prevention. In the present study, we explored the risk factors for the formation of $\mathrm{CH}$ in patients with ICH combined with 
Table 4 Risk factors for $\mathrm{CH}$ in patients with $\mathrm{ICH}$ combined with coma after emergency hematoma removal

\begin{tabular}{lccccc}
\hline Factor & B value & Standard error & Wald value & $\mathrm{P}$ value & 95\% Cl \\
\hline Modified Graeb score $\geq 5$ points & 1.758 & 0.719 & 5.985 & 0.014 & $1.419-23.732$ \\
Preoperative cerebral hernia & -1.425 & 0.822 & 3.003 & 0.083 & $0.048-1.205$ \\
Preoperative obstructive hydrocephalus & -0.801 & 0.690 & 1.349 & 0.245 & $0.116-1.734$ \\
Postoperative subdural effusion & 1.998 & 0.814 & 6.025 & 0.014 & $1.496-36.358$ \\
\hline
\end{tabular}

$\mathrm{CH}$, chronic hydrocephalus; $\mathrm{ICH}$, intracerebral hemorrhage; $\mathrm{Cl}$, confidence interval.

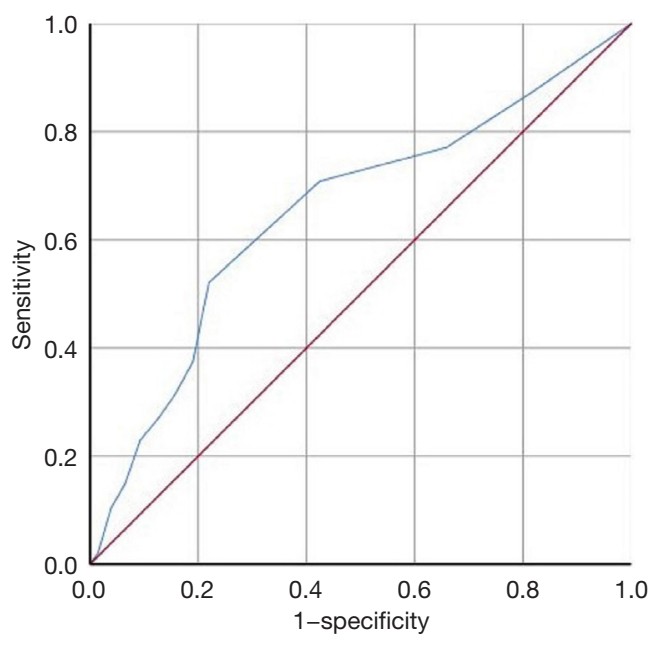

Figure 1 Diagnostic value of modified Graeb score for $\mathrm{CH}$ in patients with ICH combined with coma after emergency hematoma removal. $\mathrm{CH}$, chronic hydrocephalus; $\mathrm{ICH}$, intracerebral hemorrhage.

Table 5 Effect of $\mathrm{CH}$ on neurological function in patients with ICH combined with coma after emergency hematoma removal

\begin{tabular}{lcc}
\hline Category & $\begin{array}{c}\text { Preoperative } \\
\text { neurological deficit } \\
\text { score }\end{array}$ & $\begin{array}{c}\text { Neurological deficit } \\
\text { score at } 12 \text { months after } \\
\text { operation }\end{array}$ \\
\hline CH group $(n=48)$ & $19.75 \pm 3.03$ & $12.73 \pm 2.99$ \\
$\begin{array}{l}\text { Control group } \\
(n=205)\end{array}$ & $19.86 \pm 3.01$ & $10.64 \pm 2.82$ \\
$t$ value & 0.815 & 4.566 \\
$P$ value & 0.113 & 0.000 \\
\hline
\end{tabular}

$\mathrm{CH}$, chronic hydrocephalus; $\mathrm{ICH}$, intracerebral hemorrhage.

coma after emergency hematoma removal. The results showed that a modified Graeb score $\geq 5$ points and postoperative subdural effusion were risk factors for the formation of $\mathrm{CH}$ in patients with $\mathrm{ICH}$ combined with coma after emergency hematoma removal. The formation of $\mathrm{CH}$ affected neurological recovery.

$\mathrm{CH}$ seriously affects the neurological function of patients $(11,12)$, which is manifested as the following symptoms: (I) chronic intracranial hypertension syndrome: headache, nausea, and vomiting are not as severe as they are with acute hydrocephalus; fundus edema is often accompanied by secondary atrophy; (II) bilateral abduction paralysis; (III) mental and behavioral disorders or abnormalities, and memory loss; (IV) spastic quadriplegia is characterized by severe symptoms of the lower limbs and mild symptoms of the upper limbs; (V) endocrine abnormalities, such as obesity, sexual reproductive degeneration, or precocious puberty; and (VI) bilateral temporal hemianopia and cerebellar sign are rare. The findings of the present study also showed that the neurological deficit score of patients with $\mathrm{CH}$ increased significantly 12 months after operation, indicating that $\mathrm{CH}$ affected the recovery of neurological function.

Currently, many studies show that intraventricular hemorrhage is an independent risk factor for $\mathrm{CH}$. The modified Graeb score was revised by Morgan et al. based on the original Graeb score in 2013 (13). The modified Graeb score allows a detailed evaluation of the amount of intraventricular hemorrhage, and can semi-quantitatively evaluate the number of intraventricular hemorrhages, which better reflects the degree of ventricular dilatation $(14,15)$. In their study, Czorlich et al. analyzed 171 patients with subarachnoid hemorrhage with a survival time of more than 30 days. The results showed that the increase in Graeb score was a risk factor for the formation of $\mathrm{CH}$ in patients with subarachnoid hemorrhage (16), which supports the findings of the present study. Our study showed that a modified Graeb score $\geq 5$ points was a risk factor for the formation of $\mathrm{CH}$ in patients with ICH complicated by coma after emergency hematoma removal $(\mathrm{P}=0.014,95 \% \mathrm{CI}$ : 1.419-23.732). The modified Graeb score has certain value in the diagnosis of $\mathrm{CH}$ in patients with $\mathrm{ICH}$ combined with coma after emergency hematoma removal. 
In addition, the findings of the present study indicated that postoperative subdural effusion was a risk factor for $\mathrm{CH}$ in patients with $\mathrm{ICH}$ complicated by coma after emergency hematoma removal. Subdural effusion is defined as the accumulation of low-density liquid under the dura mater with a maximum depth of more than $0.5 \mathrm{~cm}$ from the surface of the cerebral cortex to the inner side of the scalp or skull $(17,18)$. Subdural effusion is caused by a hole between the dura mater and the arachnoid wall, and the venous reflux is blocked under high intracranial pressure, resulting in the redistribution of cerebrospinal fluid. As reported in previously published studies, subdural effusion is not only a serious complication affecting the prognosis of patients but also a risk factor for the formation of hydrocephalus (19-22). These findings support the findings of the present study.

Finally, hematoma volume may be related to $\mathrm{CH}$. But in our study, the amount of intracranial hemorrhage was not significantly related to the formation of $\mathrm{CH}$.

\section{Limitations}

Previously published studies have shown that plasma osteopontin concentration and cerebrospinal fluid output are risk factors for $\mathrm{CH}$ after ICH $(23,24)$. However, the present study was a retrospective clinical study, and we failed to study the plasma osteopontin concentration. Moreover, the immune response and blood-brain barrier injury may be risk factors for $\mathrm{CH}$ as well, but we also failed to study these.

\section{Conclusions}

A modified Graeb score $>5$ points and postoperative subdural effusion are risk factors for the formation of $\mathrm{CH}$ in patients with ICH combined with coma after emergency hematoma removal. The formation of $\mathrm{CH}$ affects postoperative neurological rehabilitation.

\section{Acknowledgments}

Funding: None.

\section{Footnote}

Reporting Checklist: The authors have completed the STARD reporting checklist. Available at https://atm.amegroups. com/article/view/10.21037/atm-22-128/rc
Data Sharing Statement: Available at https://atm.amegroups. com/article/view/10.21037/atm-22-128/dss

Conflicts of Interest: All authors have completed the ICMJE uniform disclosure form (available at https://atm. amegroups.com/article/view/10.21037/atm-22-128/coif). The authors have no conflicts of interest to declare.

Ethical Statement: The authors are accountable for all aspects of the work in ensuring that questions related to the accuracy or integrity of any part of the work are appropriately investigated and resolved. All procedures performed in this study involving human participants were in accordance with the Declaration of Helsinki (as revised in 2013). The study was approved by institutional ethics board of The Third People's Hospital of Gansu Province (No. 2020-178). Individual consent for this retrospective analysis was waived.

Open Access Statement: This is an Open Access article distributed in accordance with the Creative Commons Attribution-NonCommercial-NoDerivs 4.0 International License (CC BY-NC-ND 4.0), which permits the noncommercial replication and distribution of the article with the strict proviso that no changes or edits are made and the original work is properly cited (including links to both the formal publication through the relevant DOI and the license). See: https://creativecommons.org/licenses/by-nc-nd/4.0/.

\section{References}

1. Nie X, Cai Y, Liu J, et al. Mortality Prediction in Cerebral Hemorrhage Patients Using Machine Learning Algorithms in Intensive Care Units. Front Neurol 2021;11:610531.

2. Ponamgi SP, Ward R, DeSimone CV, et al. High Mortality Rates Among Patients With Non-Traumatic Intracerebral Hemorrhage and Atrial Fibrillation on Antithrombotic Therapy Are Independent of the Presence of Cerebral Amyloid Angiopathy: Insights From a Population-Based Study. J Am Heart Assoc 2020;9:e016893.

3. Xue LY, Gaowa S, Wang W, et al. Ventilator-associated pneumonia in patients with cerebral hemorrhage: Impact on mortality and microbiological characterization. Med Clin (Barc) 2020;154:400-5.

4. Dahaba AA, Lin H, Ye XF, et al. Propofol-Bispectral Index (BIS) Electroencephalography (EEG) PharmacokineticPharmacodynamic Model in Patients With Post-Cerebral Hemorrhage Hydrocephalus. Clin EEG Neurosci 
2021;52:351-9.

5. Siler DA, Berlow YA, Kukino A, et al. Soluble Epoxide Hydrolase in Hydrocephalus, Cerebral Edema, and Vascular Inflammation After Subarachnoid Hemorrhage. Stroke 2015;46:1916-22.

6. Bocheng W, Chaofeng L, Chuan C, et al. Intracranial lymphatic drainage discharges iron from the ventricles and reduce the occurrence of chronic hydrocephalus after intraventricular hemorrhage in rats. Int $\mathrm{J}$ Neurosci 2020;130:130-5.

7. Mijderwijk HJ, Fischer I, Zhivotovskaya A, et al. Prognostic Model for Chronic Shunt-Dependent Hydrocephalus After Aneurysmal Subarachnoid Hemorrhage. World Neurosurg 2019. [Epub ahead of print]. doi: 10.1016/j.wneu.2018.12.156.

8. Sanusi TD, McLarnon M, Abouharb A. Risk factors of chronic shunt dependent hydrocephalus following aneurysmal subarachnoid haemorrhage. Clin Neurol Neurosurg 2020;198:106095.

9. Muscas G, Matteuzzi T, Becattini E, et al. Development of machine learning models to prognosticate chronic shuntdependent hydrocephalus after aneurysmal subarachnoid hemorrhage. Acta Neurochir (Wien) 2020;162:3093-105.

10. Elsharkawy AA, Abdelhameed EA. Efficacy of translamina terminalis ventriculostomy tube in prevention of chronic hydrocephalus after aneurysmal subarachnoid hemorrhage. Surg Neurol Int 2020;11:283.

11. Shah M, Steele EA. Orbital decompression to alleviate intermittent globe subluxation due to massive optic nerve sheath enlargement from chronic hydrocephalus. Ophthalmic Plast Reconstr Surg 2013;29:e57-8.

12. Finsterer J, Kladosek A, Nagelmeier IE, et al. Chronic granulomatous meningitis with multiple cranial nerve lesions hydrocephalus, stroke, sinus thrombosis, and epilepsy. South Med J 2000;93:1108-11.

13. Morgan TC, Dawson J, Spengler D, et al. The Modified Graeb Score: an enhanced tool for intraventricular hemorrhage measurement and prediction of functional outcome. Stroke 2013;44:635-41.

14. Zheng WJ, Li LM, Hu ZH, et al. Bilateral External Ventricular Drains Increase Ventriculostomy-Associated Cerebrospinal Fluid Infection in Low Modified Graeb Score Intraventricular Hemorrhage. World Neurosurg 2018;116:e550-5.

15. Eagles ME, Jaja BNR, Macdonald RL. Incorporating a Modified Graeb Score to the Modified Fisher Scale for Improved Risk Prediction of Delayed Cerebral Ischemia Following Aneurysmal Subarachnoid Hemorrhage.
Neurosurgery 2018;82:299-305.

16. Czorlich P, Ricklefs F, Reitz M, et al. Impact of intraventricular hemorrhage measured by Graeb and LeRoux score on case fatality risk and chronic hydrocephalus in aneurysmal subarachnoid hemorrhage. Acta Neurochir (Wien) 2015;157:409-15.

17. Chang CY, Chiu TL, Chang PY, et al. Subdural effusion and ischemic stroke complicating meningococcal meningitis in an adult. J Microbiol Immunol Infect 2019;52:165-6.

18. Shahid S, Alam SH, Hadley I. An Unusual Presentation of Kikuchi-Fujimoto Disease with Recurrent Subdural Effusion. Cureus 2018;10:e2302.

19. Ozoner B, Kilic M, Aydin L, et al. Early cranioplasty associated with a lower rate of post-traumatic hydrocephalus after decompressive craniectomy for traumatic brain injury. Eur J Trauma Emerg Surg 2020;46:919-26.

20. Kim JH, Ahn JH, Oh JK, et al. Factors associated with the development and outcome of hydrocephalus after decompressive craniectomy for traumatic brain injury. Neurosurg Rev 2021;44:471-8.

21. Lu VM, Carlstrom LP, Perry A, et al. Prognostic significance of subdural hygroma for post-traumatic hydrocephalus after decompressive craniectomy in the traumatic brain injury setting: a systematic review and meta-analysis. Neurosurg Rev 2021;44:129-38.

22. Su TM, Lan CM, Lee TH, et al. Risk factors for the development of posttraumatic hydrocephalus after unilateral decompressive craniectomy in patients with traumatic brain injury. J Clin Neurosci 2019;63:62-7.

23. García-Armengol R, Puyalto P, Misis M, et al. Cerebrospinal Fluid Output as a Risk Factor of Chronic Hydrocephalus After Aneurysmal Subarachnoid Hemorrhage. World Neurosurg 2021;154:e572-9.

24. Asada R, Nakatsuka Y, Kanamaru H, et al. Higher Plasma Osteopontin Concentrations Associated with Subsequent Development of Chronic Shunt-Dependent Hydrocephalus After Aneurysmal Subarachnoid Hemorrhage. Transl Stroke Res 2021;12:808-16.

(English Language Editor: R. Scott)

Cite this article as: Yuan HT, Feng J, Wang Q. Risk factors for chronic hydrocephalus in patients with intracerebral hemorrhage complicated by coma after emergency hematoma removal. Ann Transl Med 2022;10(2):74. doi: 10.21037/atm-22-128 